\title{
En el planteamiento poliano, ¿cómo se propone la vida humana en su relación con el ser personal? Algunas implicaciones para la educación actual
}

\author{
Jorge Andrés Arango Peláez \\ Universidad de Navarra
}

\section{Introducción}

Empezaremos planteando la relación acto de ser-esencia en general para luego ver el acto de ser personal y la esencia de la persona humana. Considerando que la "vida" humana equivale a esencia formularemos las implicaciones para la educación actual: Educar es ayudar a crecer. La educación está en el ámbito de la esencia. Sin embargo, en el caso de los trascendentales personales la educación tiene una función: descubrir, aceptar; en el caso de la esencia: formar hábitos y virtudes.

La pregunta que se formula tiene una palabra por la que quisiera empezar el desarrollo de este escrito y es la palabra relación. La relación es un accidente categorial por el que algo hace referencia a otra cosa o se ordena a ella de algún modo. Es el accidente cuya naturaleza consiste en la referencia u ordenación de una sustancia a otra. En este caso es una relación entre conceptos. Eso quiere decir que es un accidente que tiene, por lo menos, dos términos o conceptos. En el caso de la pregunta que se plantea los términos o conceptos son: vida humana y ser personal. Pero el alcance de la pregunta no termina allí, porque la pone en un contexto específico, que en este caso es una propuesta filosófica concreta: el planteamiento antropológico de Leonardo Polo.

Ahora, la pregunta tiene otro término que es importante y son las "implicaciones" para un contexto específico: el de la educación actual. Si buscamos la definición de "implicaciones" nos encontramos que, en su uso común, una implicación es una afirmación que conlleva a otra, sin que la segunda deba ser comunicada explícitamente. La implicación relaciona una causa con un efecto. $Y$ esto es de lo que hablaremos en la última parte de este escrito: el "efecto" que puede llegar a tener en la educación la relación entre vida "humana" y ser personal en el planteamiento antropológico de Leonardo Polo.

Para facilitar la comprensión de la relación que nos plantea la pregunta formulada, es importante que antes hablemos de otra relación que la causa: la

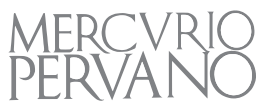


relación o, como la define Polo, distinción real de ser y esencia formulada por Tomás de Aquino. Para Polo (2003), el aporte del Aquinate, "puede ampliarse, o aprovecharse mejor si se estudia in recto en el hombre, esto es, si se distingue realmente el acto de ser humano, que es persona, de la esencia" (p. 13) de la persona humana. Pero, ¿qué es el ser y la esencia para Tomás de Aquino? El ser se refiere a lo que es, un ente, que posee una esencia determinada y el ser que es el acto por el cual el ente es.

En este sentido el ser es una perfección:

En la filosofía de Tomás de Aquino hay una reducción de todas las perfecciones a una sola, que es la perfección del ser; éste contiene en sí todas las demás perfecciones, siendo la primera y el principio de las demás, como el entender, el vivir, etc. (...). El ser es anterior y más simple que cualquiera de los bienes, valores, perfecciones que en cualquier cosa puedan hallarse; en relación con éstos, el ser es su acto. La alta perfección, valor o bien de la vida es, en cuanto tal, por su participación en el mismo ser; la plenitud de vida, o la de sabiduría, o cualquier otro atributo que consideremos, y en la medida en que lo consideremos, podrá ser por su participación en el ser. De ahí se infiere que el ser es una perfección irreductible a todas las demás; mientras estas se incardinan en la esencia determinándola y perfeccionándola de un modo u otro, la perfección del ser es extraesencial, y debe decirse que del ser participan, lo mismo que la potencia participa del acto, todas las perfecciones esenciales radicadas en un sujeto, sean estas sustanciales o accidentales. ${ }^{1}$

Tomás de Aquino es el que descubre que, en los entes reales, la composición de potencia y acto no es solamente la composición de materia y forma, sino que hay una composición más profunda: la que existe entre "lo que es" y el "ser", entre la esencia y el "acto de ser" (essentia et esse). En efecto, las esencias (clásicamente: las substancias), no existen por sí mismas. Hay un acto que las hace ser y ese acto es el esse o "acto de ser". Llamamos, pues, acto de ser a lo que hace que el ser "sea". Y llamamos esencia a lo que hace que el ser sea "lo que es". La esencia no existe realmente sin el acto de ser. Es, con el acto de ser, como la esencia existe, y es acabada. El acto de ser la comienza y la acaba, la hace perfecta. Esencia y acto de ser se distinguen realmente. Distinción real no quiere decir que la esencia pueda existir sola. Existe, es acabada, por el acto de ser.

Ahora, ¿cómo se aplica esto a la persona? Para ello vamos a empezar por decir lo siguiente: Polo (2003) plantea que "la antropología no es una ontología regional ni un capítulo de la metafísica, porque trata del ser personal, el cual no se reduce al sentido del ser que estudia la metafísica" (p.11). "El ser humano no es el ser del que se ocupa la metafísica. El ser del que se ocupa la metafísica es el ser como principio, o el sentido principal del ser". Si no es el ser del que se ocupa

\footnotetext{
1 Ángel Luis González (ed.), Diccionario de filosofía. Pamplona, Eunsa, 2010; s.v. "ser".
}

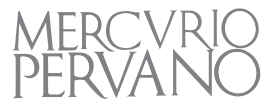


la metafísica, sino que es el ser personal, eso nos lleva a decir que el aporte de Leonardo Polo es dar un paso más allá en la propuesta tomista de la relación seresencia, de la cual ya hablamos y decir que a la persona humana le corresponden ese ser personal o ser persona humana y la esencia de la persona humana, y que al igual que los anteriores "le corresponden también trascendentales, que se han de añadir a los descubiertos por la filosofía tradicional". ${ }^{2}$

De acuerdo con Sellés, la persona humana es el acto de ser; su yo es su esencia. La esencia no es idéntica con la persona, se diferencian y se subordinan. "La esencia depende del acto de ser, no a la inversa. Su carácter activo es derivado de la persona, e inferior al de ésta. La esencia no es la persona sino de la persona. El yo [La esencia] es la raíz de todas las operaciones y acciones humanas, pero no la raíz sin más de la persona humana. El ser humano está conformado por unos radicales personales superiores al yo [la esencia]. Esos radicales conforman la persona humana". ${ }^{3}$

¿Qué quiere decir el término trascendental? Es un concepto tomado de la filosofía clásica, y más en concreto de la metafísica, son las dimensiones últimas del ser, son perfecciones puras (acto sin potencia) del ser.

La doctrina tradicional admite los siguientes trascendentales. En primer lugar, el "ente"; en segundo lugar, el "uno", al que sigue la "cosa" que son los "trascendentales absolutos". Los otros trascendentales se denominan relativos. "Algo" es un trascendental relativo en cuanto que con él se expresa la pluralidad del ente. Los otros trascendentales relativos son la "verdad", el "bien" y la "belleza". ${ }^{4}$

Siguiendo a Sellés "quiere decir que no puede existir una persona que carezca de alguna de estos radicales, son característicos de toda persona por el hecho de serlo (...). Cada uno cumple a su manera las condiciones del ser personal y se exigen mutuamente". ${ }^{5}$ Ahora, ¿cuáles son, entonces, esos trascendentales personales? Para Polo, son la coexistencia, el intelecto personal, el amar y el aceptar personales y la libertad:

Como ninguno de esos trascendentales personales es aislado, sino que entre todos conforman el acto de ser personal, al estudiarlos hay que verlos compenetrados, es decir, que no se puede entender uno haciendo abstracción de los demás. Con otras palabras: están engarzados constitutivamente entre sí, y lo están formando dualidades. Estas dualidades son dos, una inferior formada por la co-existencia y la libertad, y otra superior formada por el conocer y el amar. En cada una de ellas para explicar el radical inferior hay

\footnotetext{
2 Leonardo Polo, Antropología Trascendental. Tomo II. La persona humana. Pamplona, Eunsa, 2003, pp. 11 y 22.

${ }^{3}$ Juan Fernando Sellés, Antropología para inconformes. Madrid, Rialp, 2007, p. 509.

${ }^{4}$ Leonardo Polo, Antropología..., p. 33.

${ }^{5}$ Juan Fernando SelLés, Antropología..., p. 514.
} 
que aludir al superior. Así, no se entiende la co-existencia sin la libertad personal, y no se puede explicar el conocer sin atender al amar. A la par, la dualidad inferior es incomprensible sin la superior, pues sería absurda una apertura íntima que no fuese cognoscitiva y amante; una libertad sin conocimiento no es personal; una libertad desamorada, tampoco. De manera que, ni son ni se pueden entender por separado. ${ }^{6}$

Ya hemos hablado del ser personal o del acto de ser que es la persona humana. Pasemos ahora a hablar de la esencia de la persona humana y explicar por qué cuando la pregunta utiliza la palabra "vida" humana, está haciendo referencia a la esencia de la persona humana. El doctor Polo, en su Antropología Trascendental, dedica un capítulo a reflexionar sobre "La esencia de la persona humana", y dice lo siguiente: "según mi propuesta, el vivir humano está en el nivel esencial: es la manifestación del viviente humano" (p. 13).

En ese sentido es adecuado ahondar un poco a la manera como lo hace Sellés, que distingue entre vida natural humana, vida esencial humana y vida personal humana:

La vida natural humana es el vivificar del alma al cuerpo, y lo vivifica temporalmente, pues su tarea termina (de momento) con la muerte. La vida natural humana aúna la vida vegetativa de nuestras células y la vida sensitiva de nuestros órganos. La vida personal humana, en cambio, es la vida espiritual, la de cada persona humana que dispone de todas aquellas funciones y facultades de la vida natural (...). Esta vida personal [humana] no vivifica directamente al cuerpo y a las diversas potencias y perdura tras la muerte. Advertir eso será dar el paso de la vida biológica (la vegetativa y sensible) a la vida espiritual. Además (...), la vida personal [humana] de cada quién activa la vida intelectual de nuestras potencias superiores inmateriales (inteligencia y voluntad) (...), y que, aunque vinculada a la vida natural [humana], no depende de ella para su crecimiento. A la vida natural humana se puede llamar vida recibida, pues la biología que conforma nuestra corporeidad la hemos recibido de nuestros padres; es nuestra dotación genética. En cambio, a la vida que cada persona humana añade sobre la vida natural recibida, y también sobre las potencias espirituales, la podemos denominar vida añadida. La primera, la vida recibida, es el compuesto somático, celular, que recibimos de nuestros progenitores por generación. En efecto, de ellos recibimos el cuerpo, no la persona que cada uno es (...). La segunda, la vida añadida, en cambio, es el partido que nosotros, cada quién, sacamos de nuestras facultades, en especial de las potencias superiores (...). La clave de la vida natural [humana] es el crecimiento. Crecer también es el fin de la vida intelectual y volitiva. Pero a nivel de vida personal [humana] no cabe hablar, en sentido estricto, de crecimiento, porque uno no llega a ser más

\footnotetext{
${ }^{6}$ Juan Fernando SelLÉs, Antropología..., p. 513.
}

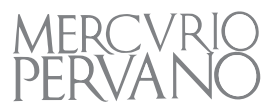


persona de lo que es por sus propias fuerzas. Sin embargo, si puede aceptar ser más persona si ese más personal le es concedido (...). La vida humana no es pues, sólo cuestión de biología y de psicología, porque, opuestamente a la del resto de los vivientes, su vida personal [humana] desborda la vida natural [humana] y esencial [humana]. En efecto, añade a ellas la vida personal [humana], que integra a las restantes. ${ }^{7}$

La esencia humana es la fuente que activa progresivamente, y de un modo u otro, la inteligencia y la voluntad, y a través de éstas modula de un modo u otro la naturaleza orgánica humana (...). La esencia es el principio de lo que vivifica, sea lo vivificado natural o intelectual. Esta distinción es todavía más aguda que la que media entre vida personal [humana] y la vida natural [humana], porque la esencia humana es más perfecta, más acto, que la vida natural [humana], pero menos que la vida personal [humana]. ${ }^{8}$

Para complementar el tema de la vida "humana", quisiera recoger unas palabras de Leonardo Polo (2011) al respecto:

El hombre dispone según su esencia, no dispone de su esencia; el hombre no se cierra a sí mismo en identidad ser-esencia, porque en ese momento el hombre se quedaría solo, y ya he dicho que la soledad es lo más contrario al ser personal. Por lo tanto, lo que el hombre sí puede hacer, y en eso está el sentido de su propia esencia, es crecer, perfeccionarse, autoperfeccionarse. Es decir, como crecimiento, el sentido de la vida humana está justamente en manifestar cada vez mejor a la persona; porque a través de su esencia el ser humano se puede manifestar. Lo que no puede es encontrarse entero en lo que es una manifestación suya; eso nunca lo puede hacer. La persona no se agota en su esencia, la persona en este sentido trasciende su esencia; aquí lo trascendental es un trascender la propia esencia, que es justamente lo que hace que el intento de disponer de ella sea un intento empobrecedor: el hombre de esa manera se reduce, se confunde, y se equivoca. ${ }^{9}$

Pero, ¿cómo puede perfeccionarse la persona? Puede perfeccionarse de la siguiente manera de acuerdo con Polo:

En el caso del hombre, aun considerado como sustancia natural, la perfección es intrínseca, es decir, el hombre es una sustancia natural capaz de autoperfección. Si la sustancia natural humana es capaz de autoperfección, entonces esa capacidad de autoperfeccionarse, y ese efectivo alcanzar la propia perfección, es justamente lo que yo entiendo como esencia del hombre. La esencia del hombre se distingue de la esencia universo en cuanto

\footnotetext{
${ }^{7}$ Juan Fernando Sellés, Antropología..., p. 30.

${ }^{8}$ Juan Fernando SelLés, Antropología..., p. 37.

9 Leonardo Polo, La esencia del hombre. Pamplona, Eunsa, 2011, p. 231.
} 
que esencia, en que ella misma se dota de perfección, en que la perfección le es intrínseca. Se constituye como esencia sin aludir a un factor extrínseco ordenante, o a un sentido causal ordenante, sino que consigue su perfección, digámoslo así, en una redundancia sobre sí misma. Y esa redundancia sobre sí misma es justamente lo que se suele llamar hábito. El hábito es la perfección de la naturaleza humana. Pero el hábito se distingue de la causa final, de la unidad de orden, es decir, de la perfección del universo, porque el hábito no es extrínseco a la naturaleza, sino que el hábito es una consecuencia de la naturaleza. Al desplegar el hombre su operatividad natural, entonces adquiere hábitos: o bien los hábitos intelectuales, o bien los hábitos de la voluntad, que son las llamadas virtudes morales, y también incluso las tenencias categoriales. Una naturaleza que es capaz de autoperfección, una naturaleza que no tiene su fin fuera de ella misma, por decirlo así, sino que se dota ella misma de su propia perfección, esa naturaleza no es del universo, sino superior al universo. Una naturaleza autoperfectible no es la esencia universo, sino que es otro tipo de esencia. ${ }^{10}$

En ese orden de ideas pasemos a la última parte de la pregunta: qué implicaciones tiene todo esto para la educación actual. En primer lugar, quisiera decir que, para Polo, educar es ayudar a crecer -acudiendo a una definición de Tomás Alvira-. Si educar es ayudar a crecer, la palabra crecimiento nos remite a la esencia de la persona humana, eso quiere decir, entre otros aspectos, que la educación está llamada a dar y ayudarle a descubrir a cada persona aquello le ayude a desarrollar su esencia. Y ese desarrollo de la esencia tiene un fin concreto que es el de formar y adquirir hábitos. "La adquisición de hábitos constituye la última fase del crecimiento de la persona, la más alta e intrínseca del crecimiento humano, porque los hábitos son perfeccionamientos de las facultades superiores, es decir, de la inteligencia y de la voluntad". ${ }^{11}$ Es el fin de la vida añadida.

Por último, me voy a atrever a plantear que, en el caso de los trascendentales personales, la educación también puede aportar. Está claro que los trascendentales personales no pueden crecer, si son acto, no están llamados a crecer, simplemente están ahí, uno no llega a ser más persona por sus propias fuerzas; sin embargo, sí que es verdad que una buena educación ayuda a la persona a descubrirse y aceptarse como quién es (coexistencia, libertad, amor, conocimiento). Y yendo un poco más allá, que cada uno descubra y acepte lo que son los demás.

\footnotetext{
${ }^{10}$ Leonardo Polo, La esencia del hombre, p. 224.

${ }^{11}$ Leonardo Polo, Ayudar a crecer. Cuestiones filosóficas de la educación. Pamplona, Eunsa, 2006, p. 59.
}

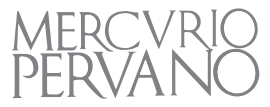




\section{Referencias Bibliográficas}

GonzÁlez, Ángel Luis (ed.), Diccionario de filosofía. Pamplona, España: Eunsa, 2010.

Polo, Leonardo, Antropología Trascendental. Tomo I. La persona humana. Pamplona, Eunsa, 2003.

- - Antropología Trascendental. Tomo II. La esencia de la persona humana. Pamplona, Eunsa, 2003.

-—, Ayudar a crecer. Cuestiones filosóficas de la educación. Pamplona, Eunsa, 2006.

—_, La esencia del hombre. Pamplona, Eunsa, 2011.

Sellés, Juan Fernando, Antropología para inconformes. Madrid, Rialp, 2007. 